\title{
Availability of Recreational Resources in Minority and Low Socioeconomic Status Areas
}

\author{
Latetia V. Moore, PhD, Ana V. Diez Roux, MD, PhD, Kelly R. Evenson, PhD, Aileen P. McGinn, PhD,
} Shannon J. Brines, MEng

Background: Differences in availability of recreational resources may contribute to racial and socioeconomic status (SES) disparities in physical activity. Variations in the location and density of recreational resources were examined by SES and racial composition of neighborhoods.

Methods: Densities of resources available in recreational facilities and parks were estimated for census tracts between April 2003 and June 2004 in North Carolina, New York, and Maryland using kernel estimation. The probability of not having a facility or park was modeled by tract racial composition and SES, adjusting for population and area, using binomial regression in 2006. Mean densities of tract resources were modeled by SES and racial composition using linear regression.

Results: Minority neighborhoods were significantly more likely than white neighborhoods not to have recreational facilities (relative probability $[\mathrm{RP}]=3.27[95 \% \mathrm{CI}=2.11-5.07]$ and 8.60 [95\% CI $=4.48-16.51]$, for black and Hispanic neighborhoods, respectively). Low-income neighborhoods were 4.5 times more likely to not have facilities than high-income areas $(95 \% \mathrm{CI}=2.87-7.12)$. Parks were more equitably distributed. Most resources located in recreational facilities required a fee and were less dense in minority and low-income areas. Those located inside parks were usually free to use, sports-related, and denser in poor and minority neighborhoods.

Conclusions: Recreational facilities and the resources they offer are not equitably distributed. The presence of parks in poor and minority areas suggest that improving the types and quality of resources in parks could be an important strategy to increase physical activity and reduce racial/ethnic and socioeconomic disparities.

(Am J Prev Med 2008;34(1):16-22) @ 2008 American Journal of Preventive Medicine

\section{Introduction}

I $\mathrm{n}$ the context of the growing epidemic of obesity in the United States ${ }^{1}$ and with only $3.0 \%$ of Americans engaging in a fully healthy lifestyle,,$^{2}$ the modification of obesogenic environments to stimulate healthier living has emerged as a potentially important target for intervention and policy. The concept that environments may enable people to be physically active has been supported by cross-sectional studies showing a relationship between the built environment and physically activity. ${ }^{3-19}$ While the availability of a supportive physical environment may not in itself be sufficient to promote activity, it is likely to enhance individual-

From the Department of Epidemiology (Moore, Diez Roux), School of Natural Resources (Brines), University of Michigan, Ann Arbor, Michigan; Department of Epidemiology (Evenson), University of North Carolina, Chapel Hill, North Carolina; Department of Epidemiology and Population Health (McGinn), Albert Einstein College of Medicine, Bronx, New York

Address correspondence and reprint requests to: Ana V. Diez Roux, MD, PhD, Department of Epidemiology, 1214 South University, 2nd Floor, Ann Arbor MI 48103. E-mail: adiezrou@umich.edu. targeted strategies. ${ }^{7,20-26}$ For these reasons, environmental features such as the lack of physical activity opportunities in neighborhoods have been hypothesized to be important contributors to physical activity at the population level. ${ }^{3,15,16,24,25}$

There are important disparities in leisure-time physical activity by race/ethnicity and socioeconomic position. ${ }^{27-30}$ Non-Hispanic blacks, Hispanics, and people with lower education levels are often less physically active than whites and those with higher education. ${ }^{28-30}$ Differences in the availability of recreational resources across residential environments could contribute to these disparities. However, data on the relationship between area socioeconomic status (SES) characteristics and physical activity resources remain sparse and inconsistent, ${ }^{12,31-36}$ and few studies have investigated the role of residential racial/ethnic segregation in addition to SES characteristics. This study used data from three diverse areas in the U.S. to examine the spatial availability of a variety of recreational resources by neighborhood income and race/ethnicity. In contrast to prior work, not only was the presence of resources examined, but also the densities and types of resources. 


\section{Methods}

The study area included a total of 685 census tracts, also referred to as tracts or neighborhoods, in Baltimore city and county, Maryland (276 tracts); Forsyth County, North Carolina (75 tracts); and Manhattan and the Bronx, New York (334 tracts). Census tracts are subdivisions of counties with a mean population of approximately 4000 people that are relatively homogeneous in socioeconomic characteristics. ${ }^{37}$ This study area represents tracts in a larger study of neighborhood determinants of cardiovascular risk. ${ }^{17,38,39}$ The location of recreational resources was obtained from online Yellow Page and Internet searches, departments of city planning and recreation, and local geographic information system (GIS) units between April 2003 and June 2004. Resources surveyed included 400 public-use parks ranging in size from 1 to 15,054 square miles (median 4 ) and 499 commercial and public recreational facilities. Resources located on school property or churches, trails not within parks or recreational facilities, and private facilities located in hotels or apartment buildings were not surveyed. The types of indoor and outdoor resources available at each park or facility designated for adult use were recorded. Information on counts was obtained for selected resources (tracks, roller and ice skating rinks, skate parks, pools, tennis courts, racquetball/squash courts, general sports fields, baseball, cricket, and football fields). The total number of resources available at each facility and park was obtained by summing the resources at each location, weighted by the count when appropriate. Resources were assumed to be evenly distributed in space over the park. Information on whether the facility required usage fees was obtained through web searches and phone calls.

Densities of recreational resources per area were estimated by the kernel density method ${ }^{40,41}$ using ArcGIS v.9.2. Densities were estimated based on point locations of recreational facilities and polygons of parks, weighted by the number of different types of resources and the counts of those resources. Each recreational facility and park was represented on a map by a smoothed cone (kernel) centered at that location. The radius of the cone represents the window size ( 1 mile in this study). One-mile windows were used because most physically active adults surveyed in these areas reported using resources within 1 mile of their home. ${ }^{17}$ Larger heights and total volumes of cones indicate greater availability of resources at a location. The density of resources is highest at the point location and declines the further a resource is from the center following a bivariate normal distribution, or quartic

Table 1. Selected characteristics of census tracts by tract racial/ethnic composition and median household income

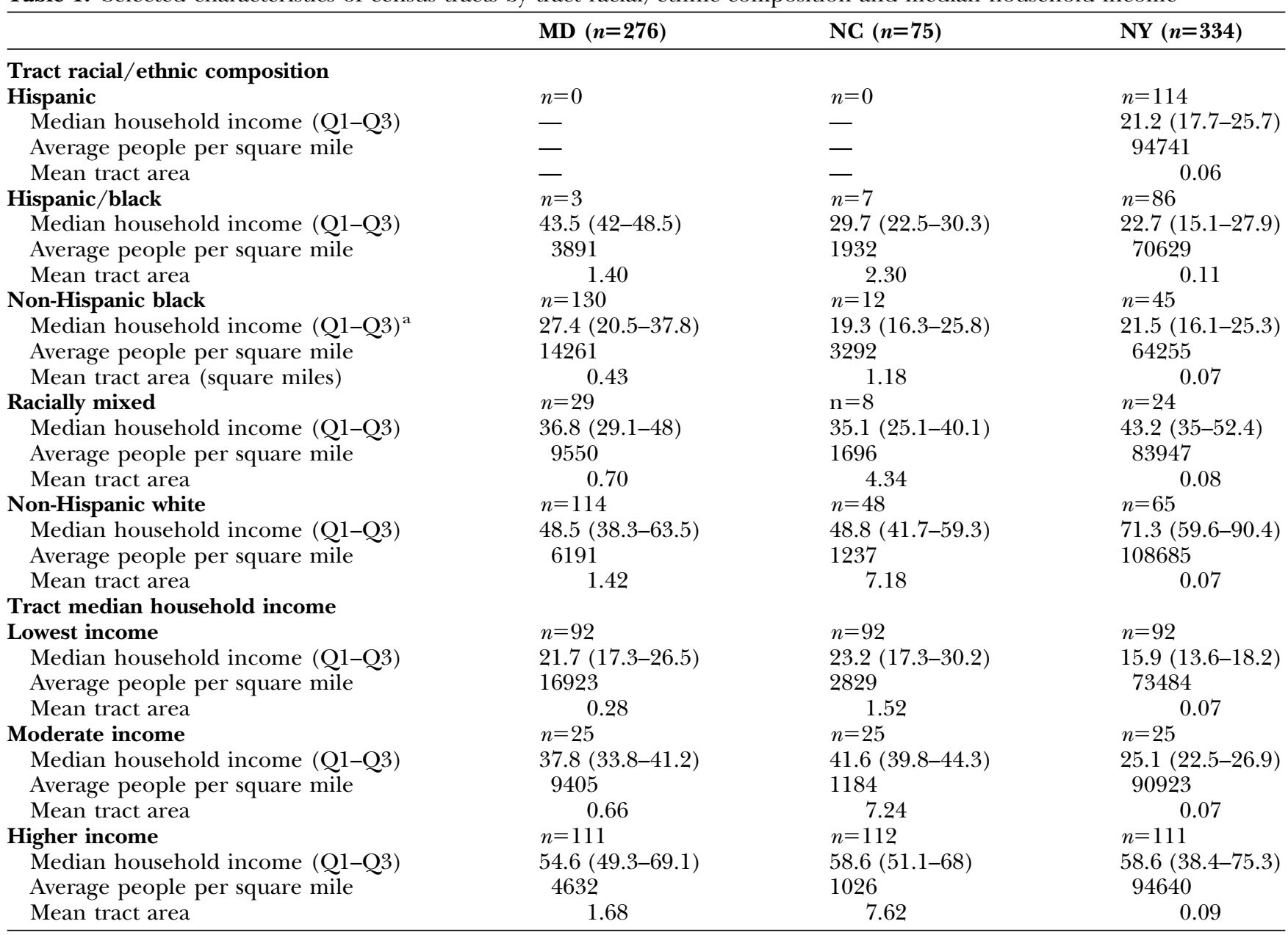

${ }^{\text {a }}$ Thousands of dollars; Q1 $-25^{\text {th }}$ percentile; Q3 $-75^{\text {th }}$ percentile.

MD, Maryland; NY, New York; NC, North Carolina. 
kernel. ${ }^{41}$ Cones for different resources overlap when less than two miles apart. Each study area was partitioned into 100meter grid cells and the density value of each cell was assigned by summing the densities corresponding to each of the overlapping cones. The mean density for the tract was estimated by taking the mean of the 1-mile kernel densities for all grid cells located within the census tract. ${ }^{40}$ This procedure accounts for the fact that points located on the border of the tract will have access to resources located in adjacent tracts as long as the resources in adjacent tracts fall within a mile of the point location.

Densities were investigated for two categories of resources: (1) resources offered by parks and (2) resources offered by recreational facilities. Population-adjusted densities (resources per 100,000 people) were estimated by dividing the resource density for each cell by the corresponding population density created from census block data using similar methods. The average population-adjusted density for the tract was estimated by taking the means of the populationadjusted densities for all cells within the tract. ${ }^{40}$

Information on tract characteristics including population, land area, racial/ethnic composition, and median household income was obtained from the Year 2000 U.S. Census. ${ }^{42}$ Census tracts with greater than $60 \%$ of the residents in a particular racial/ethnic group were defined as either predominantly non-Hispanic white, predominantly non-Hispanic black, predominantly Hispanic, or predominantly Hispanic/ black areas. Tracts that did not fall into any of these categories were classified as racially mixed areas. Tracts were also stratified into lowest income, moderate income, or wealthiest based on tertiles of tract median household income.

Associations of tract racial/ethnic and socioeconomic composition with the presence and density of different types of resources were examined in two sets of ecologic analyses. In the first set of analyses, the probability of not having a recreational facility or a park in a tract was modeled as a function of tract socioeconomic and race/ethnic composition separately, adjusting for tract area, population, and site sequentially using binomial regression. ${ }^{43}$ In a second set of analyses, the mean density of resources in the tract was modeled by tract characteristics using linear regression. Be-

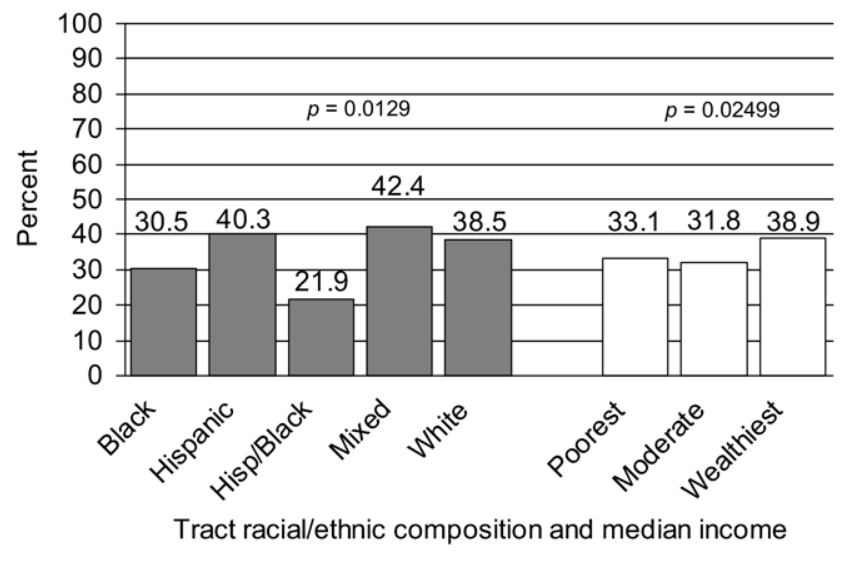

Figure 1. Percent of tracts without a park by racial/ethnic composition and median household income adjusted for tract area. Proportions were adjusted to the mean area of the tracts using logistic regression. cause of their skewed distribution, densities were logged for analysis; hence, exponentiated coefficients are interpretable as relative differences or percent differences in mean densities associated with differences in tract characteristics. Associations of tract characteristics with densities were examined before and after adjustment for site. Interactions of tract race and tract household income with site were tested by including appropriate interaction terms in the models. All statistically significant interactions of tract income and racial composition with site were investigated in site-specific analyses, but only those with a clear qualitative difference by site are reported.

\section{Results}

Minority and lower-income tracts were generally more densely populated than predominantly white and higherincome tracts, except in New York where the highest population density was observed in predominantly white and high-income tracts (Table 1). Predominantly white and higher-income tracts also were generally larger in size than other tracts, except in New York where differences were small. Median household income was lower for minority tracts than for white tracts.

Most minority tracts $(70 \%-80 \%)$ did not have a recreational facility in the tract compared to $38 \%$ of white tracts $(p<0.0001)$ (Figure 1$)$. Poorer tracts were also less likely to have a facility than wealthier tracts (Figure 1: $74 \%$ vs $46 \%$, in wealthiest vs poorest tracts; $p$-value for trend $<0.0001)$. In contrast, the proportion of tracts that did not have a park was generally similar across income and racial/ethnic composition (Figure 2), except for Hispanic/black tracts, which had fewer parks.

Relative probabilities of not having a facility or a park in the tract by tract racial/ethnic composition and income adjusted for tract area, population, and site are shown in Table 2. After adjustment for area, popula-

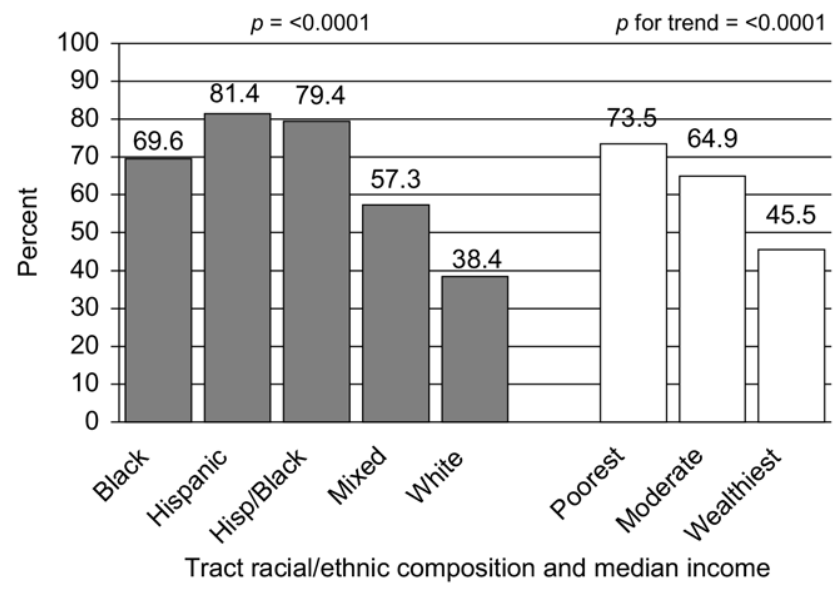

Figure 2. Percent of tracts without a recreational facility by racial/ethnic composition and median household income adjusted for tract area. Proportions were adjusted to the mean area of the tracts using logistic regression. 
Table 2. Adjusted relative probabilities (95\% CIs) of not having a park and of not having a facility in the census tract by tract racial/ethnic composition and median household income

\begin{tabular}{|c|c|c|c|c|}
\hline & \multicolumn{2}{|c|}{ Relative probabilities of not having a park } & \multicolumn{2}{|c|}{ Relative probabilities of not having a facility } \\
\hline Hispanic & $1.07(0.66-1.74)$ & $0.95(0.55-1.63)$ & $9.12(4.99-16.68)$ & $8.60(4.48-16.51)$ \\
\hline Hispanic/black & $0.45(0.26-0.79)$ & $0.41(0.22-0.76)$ & $6.59(3.64-11.94)$ & $6.67(3.52-12.64)$ \\
\hline Black & $0.71(0.46-1.08)$ & $0.69(0.45-1.06)$ & $3.30(2.14-5.10)$ & $3.27(2.11-5.07)$ \\
\hline \multicolumn{5}{|c|}{ Tract median income } \\
\hline Poorest & $0.72(0.48-1.08)$ & $0.73(0.48-1.11)$ & $4.65(3.01-7.19)$ & $4.52(2.87-7.12)$ \\
\hline Moderate & $0.70(0.47-1.04)$ & $0.73(0.49-1.08)$ & $2.50(1.69-3.70)$ & $2.74(1.84-4.09)$ \\
\hline Wealthiest & 1.00 & 1.00 & 1.00 & 1.00 \\
\hline
\end{tabular}

tion, and site, Hispanic/black and Hispanic neighborhoods were seven to nine times more likely than white neighborhoods to not have a facility in the area (relative probability $[\mathrm{RP}]=6.67,95 \% \mathrm{CI}=3.52-12.64 ; \mathrm{RP}=8.60$, $95 \% \mathrm{CI}=4.48-16.51$, respectively). The probability of not having a facility in the neighborhood was also significantly higher for black and racially mixed areas compared to white areas $(\mathrm{RP}=3.27 ; 95 \% \mathrm{CI}=2.11-5.07$ and $\mathrm{RP}=2.27 ; 95 \% \mathrm{CI}=1.24-4.14$, respectively). Lower income was also associated with a higher probability of not having a facility (RP for low- and middle-income compared to high-income tracts, respectively, $\mathrm{RP}=4.52$, $95 \% \mathrm{CI}=2.87-7.12 ; \mathrm{RP}=2.74,95 \% \mathrm{CI}=1.84-4.09)$. Parks were generally equitably distributed across categories of tract median income and racial/ethnic composition with the exception of Hispanic/black neighborhoods, which were less likely to intersect a park. Associations of tract characteristics with facilities and parks were generally qualitatively similar across sites (not shown).

Forty-eight different types of resources were offered by parks and recreational facilities. The majority of the resources offered by parks were sports-related (92\%) and free for public use (87\%). Parks offered resources

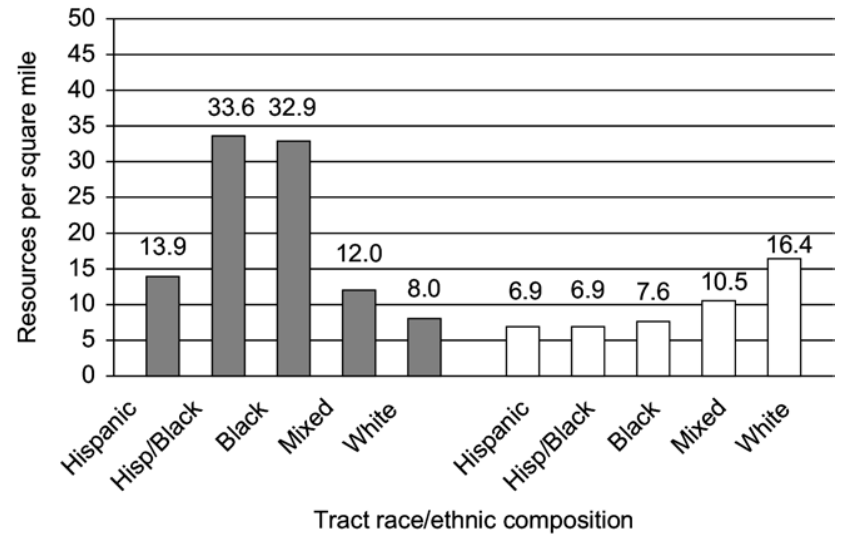

Figure 3. Mean densities of resources by tract racial/ethnic composition. for baseball, boating, bocce ball, canoeing, cricket, football, golf, horseshoes, basketball, roller and ice skating, racquetball, soccer, skiing, tennis, and volleyball, as well as beaches, fields, pools, skate parks, tracks, and trails. Crude densities of park resources were significantly higher in minority and low-income tracts than in white and high-income tracts (Figures 3 and 4). Minority and low-income tracts had greater densities of park resources even after adjustment for population and site (Table 3; relative difference $[\mathrm{RD}]=1.21-1.48$ for predominantly minority tracts and 1.67 for lowincome tracts).

Recreational facilities offered a myriad of resources, half of which were sports-related, and virtually all of which required a fee for use $(99 \%)$. Resources included aerobics, batting cages, bowling, boxing, cardiovascular equipment, dancing, disc golf, fencing, golf courses and ranges, gymnastics, basketball, tennis, pools, volleyball, malls with walking programs, martial arts, personal training facilities, Pilates, racquetball, tai-chi, roller and ice skating, skate parks, tracks, wall climbing, weight training, and yoga. Densities of facility resources were lower in minority and low-income areas than in white areas and high-income areas (Figures 3 and 4). These

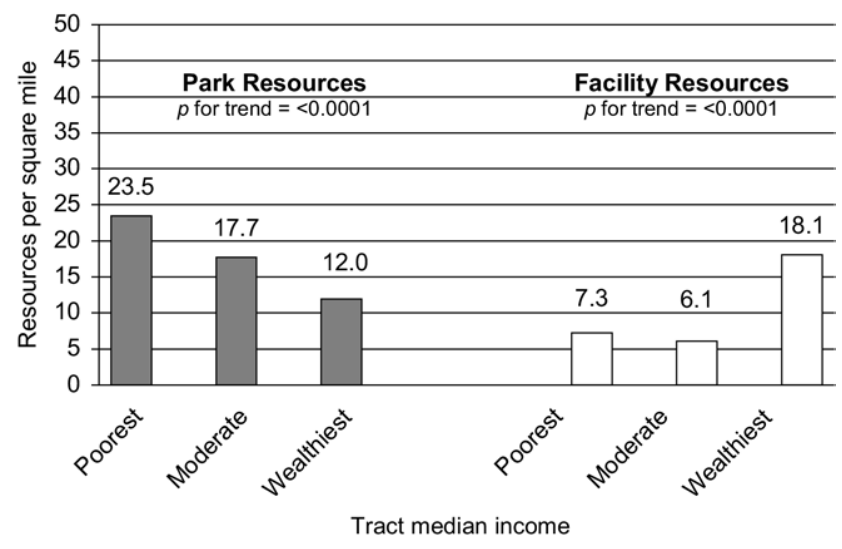

Figure 4. Mean densities of resources by tract median household income. 
Table 3. Adjusted relative differences (95\% CIs) in recreational resource densities by tract racial/ethnic composition and median household income

\begin{tabular}{|c|c|c|c|c|}
\hline & \multicolumn{2}{|c|}{ Resources in parks } & \multicolumn{2}{|c|}{ Resources in facilities } \\
\hline \multicolumn{5}{|c|}{ Tract race/ethnicity } \\
\hline Hispanic & $1.15(0.94-1.41)$ & $1.31(1.04-1.64)$ & $0.14(0.11-0.19)$ & $0.16(0.11-0.22)$ \\
\hline Hispanic/black & $1.38(1.11-1.71)$ & $1.48(1.17-1.87)$ & $0.18(0.13-0.25)$ & $0.20(0.14-0.28)$ \\
\hline White & 1.00 & 1.00 & 1.00 & 1.00 \\
\hline \multicolumn{5}{|c|}{ Tract median income } \\
\hline Poorest & $1.57(1.33-1.85)$ & $1.67(1.41-1.97)$ & $0.28(0.22-0.36)$ & $0.36(0.27-0.46)$ \\
\hline Moderate & $1.29(1.10-1.52)$ & $1.34(1.14-1.57)$ & $0.33(0.26-0.43)$ & $0.36(0.28-0.46)$ \\
\hline Wealthiest & 1.00 & 1.00 & 1.00 & 1.00 \\
\hline
\end{tabular}

Note: $95 \%$ confidence interval obtained by exponentiating regression coefficients from models with the log of the density as the outcome. A relative difference of 1.5 indicates that one unit increase in the independent variable is associated with a $50 \%$ increase in the density.

associations remained $61 \%-84 \%$ lower in minority and low-income tracts than in white and wealthy tracts after adjustment for population and site (Table 3).

In site-specific population-adjusted analyses, significantly higher densities of park resources in predominantly black and low-income areas were observed in North Carolina and New York $(\mathrm{RD}=2.69$ and 1.75, respectively, for black vs white areas, and 3.17 and 1.62 for low- vs high-income areas) but not in Maryland $(\mathrm{RD}=0.89$ for black and 1.39 for low income) ( $p$-value for interaction $<0.0001)$. Lower densities of facility resources in predominantly black and low-income areas were clearly observed in Maryland and New York, but not in North Carolina (RD for predominantly black areas versus white areas $=0.33,0.41$, and 0.96 in Maryland, New York, and North Carolina, respectively, $p$-value interaction $<0.0001$; RD for low-income vs high income $=0.73,0.19$, and 1.00 in Maryland, New York, and North Carolina, respectively, $p$-value interaction $<0.0001$ ) (data not shown).

\section{Discussion}

The results of this study indicate that the location and the density of recreational resources are differentially distributed across levels of area income and racial/ ethnic composition. Recreational facilities were significantly less common in lower-income and minority neighborhoods while parks were more equitably distributed. The resources offered by parks were predominantly sports-related and free to use, and were often denser in minority and low-income areas than in white and high-income areas. In contrast, densities of resources offered by recreational facilities, almost all of which required a fee for use, were significantly higher in white and higher-income areas.

There was some evidence of heterogeneity by site. Higher densities of park resources in black and low- income areas were observed in North Carolina and New York, but not in Maryland. Densities of facility resources were significantly lower in black and low-income areas in Maryland and New York, but not in North Carolina. These regional differences may be related to the history of residential segregation in different areas and its relationship to the location of parks and commercial areas. In addition, parks in different regions may be administered and funded through different mechanisms (e.g., general taxes versus special tax districts) that may affect their location as well as the amount and quality of resources they offer. ${ }^{44}$ These results, however, do point to a general pattern: overall, black and Hispanic areas and low-income areas had fewer recreational facilities, but more parks and consequently either equal or greater access to the types of resources (mostly sports-related) offered in parks.

Similar to these findings, a large study using data from the National Longitudinal Study of Adolescent Health found that higher-SES and low-minority block groups were significantly more likely to have facilities than low SES and minority block groups. ${ }^{33}$ But not all studies have replicated these findings. In a study of 32 census tracts in the Midwest, Estabrooks et al. ${ }^{31}$ found that neighborhoods did not differ in the number of pay-for-use parks, sport facilities, fitness clubs, community centers, and walking/biking trails; however, lowSES neighborhoods had significantly fewer free-for-use resources. Wilson et al. ${ }^{32}$ found that while respondents in lower-SES areas in a southeastern county reported less availability of public recreational facilities, the perception of less availability was not substantiated by GIS data. Talen ${ }^{34}$ found that low availability of parks was spatially patterned by housing value and the percentage of nonwhite residents in census block groups but associations differed qualitatively by site. Wolch et al. $^{35}$ reported that fewer parks were available in minority and low-income census tracts in Los Angeles. 
In this study, most resources located in recreational facilities required a fee and were less common in minority and low-income areas. Those located inside parks were usually free to use and were either equitably distributed across neighborhoods or more common in poor and minority neighborhoods. Differences in results across studies could result in part from differences in the types of resources investigated and in the way they were characterized. In addition, the spatial patterning is not necessarily invariant across regions. The bulk of the literature seems to suggest that recreational facilities in the U.S. and the types of resources they provide appear to be less common in low-income and minority areas. Results for public parks were not as consistent.

A limitation of these analyses is the lack of data on the quality of the resources available. While parks may be equitably distributed across neighborhoods, the quality of the parks may be highly variable. All types of investigated resources were given the same weight although some activities are done more frequently than others. Information on resources in apartment complexes, hotels, school properties, and churches were not collected. Data from adults surveyed in the same areas showed that less than $2 \%$ of adults reported exercising in schools or churches so these omissions are unlikely to be significant venues for physical activity in this population.

This study went beyond prior work that simply documents the presence or absence of facilities ${ }^{31-33}$ to examine the types and numbers of resources available. However, differences in the cost or attractiveness of resources (which may be more important than spatial availability in affecting utilization) were not investigated. Although three diverse areas were studied, findings may not be generalizable to all U.S. regions. In particular, the Hispanic and Hispanic/black neighborhoods represent primarily the New York site; these associations may not be generalizable to other areas with Hispanic populations.

One of the objectives of Healthy People $2010^{45}$ is to increase opportunities for physical activity by enhancing access to places and facilities where people can be physically active. This study found that poor and minority areas were less likely to have recreational facilities (and the diverse resources these establishments offer), but parks were equitably distributed or more common in these areas. The primarily sports-related resources offered in parks may not necessarily be the types of resources needed for the population as a whole to maintain a sufficiently active lifestyle. For example, $92 \%$ of the types of activities offered in parks in this study were sports-related, while only $4 \%$ of older adults sampled from this area report engaging in any type of sporting activity. ${ }^{17}$ Policies aimed at improving the types and quality of resources available in parks could be an important strategy to increase physical activity and reduce racial/ethnic and socioeconomic disparities. Evidence on what specific changes in the availability and accessibility of resources that most affect physical activity is needed in order to recommend the most effective environmental interventions to promote physically active lifestyles and reduce health disparities.

This study was funded in part by the Columbia Center for the Health of Urban Minorities: (MD00206) from NCMHD (NIH) and by R01-HL071759 (Diez Roux PI) from NHLBI.

No financial disclosures were reported by the authors of this paper.

\section{References}

1. Flegal KM, Carroll MD, Ogden CL, Johnson CL. Prevalence and trends in obesity among U.S. adults, 1999-2000. JAMA 2002;288:1723-7.

2. Reeves MJ, Rafferty AP. Healthy lifestyle characteristics among adults in the United States, 2000. Arch Intern Med 2005;165:854-7.

3. Humpel N, Owen N, Leslie E. Environmental factors associated with adults' participation in physical activity: a review. Am J Prev Med 2002;22: 188-99.

4. Brownson RC, Baker EA, Housemann RA, Brennan LK, Bacak SJ. Environmental and Policy determinants of physical activity in the United States. Am J Public Health 2001;91:1995-2003.

5. Hoehner CM, Ramirez LKB, Elliott MB, Handy SL, Brownson RC. Perceived and objective environmental measures and physical activity among urban adults. Am J Prev Med 2005;28:105-16.

6. Martin S, Elosua R, Covas MI, Pavesi M. Relationship of lipoprotein(a) levels to physical activity and family history of coronary heart disease. Am J Public Health 1999;89:383-5.

7. Bauman AE, Sallis JF, Dzewaltowski DA, Owen N. Toward a better understanding of the influences on physical activity: the role of determinants, correlates, causal variables, mediators, moderators, and confounders. Am J Prev Med 2002;23(2S):5-14.

8. Giles-Corti B, Donovan RJ. Relative influences of individual, social environmental, and physical environmental correlates of walking. Am J Public Health 2003;93:1583-9.

9. Booth KM, Pinkston MM, Poston WSC. Obesity and the built environment J Am Diet Assoc 2005;105:S110-7.

10. King WC, Belle SH, Brach JS, Simkin-Silverman LR, Soska T, Kriska AM. Objective measures of neighborhood environment and physical activity in older women. Am J Prev Med 2005;28:461-9.

11. van Lenthe FJ, Brug J, Mackenbach JP. Neighbourhood inequalities in physical inactivity: the role of neighbourhood attractiveness, proximity to local facilities and safety in the Netherlands. Soc Sci Med 2005;60: $763-75$.

12. Giles-Corti B, Donovan RJ. Socioeconomic status differences in recreational physical activity levels and real and perceived access to a supportive physical environment. Prev Med 2002;35:601-11.

13. Sallis JF, Hovell MF, Hofstetter CR, et al. Distance between homes and exercise facilities related to frequency of exercise among San Diego residents. Public Health Rep 1990;105:179-85.

14. Huston SL, Evenson KR, Bors P, Gizlice Z. Neighborhood environment, access to places for activity, and leisure-time physical activity in a diverse North Carolina Population. Am J Health Promot 2003;18:58-69.

15. Popkin BM, Duffey K, Gordon-Larsen P. Environmental influences on food choice, physical activity and energy balance. Physiol Behav 2005;86: 603-13.

16. Jackson L. The relationship of urban design to human health and condition. Landsc Urban Plan 2002;993:1-10.

17. Diez-Roux AV, Evenson KR, McGinn AP, et al. Availability of recreational resources and physical activity in adults. Am J Public Health 2007;97:493-9.

18. Saelens BE, Sallis JF, Black JB, Chen D. Neighborhood-based differences in physical activity: an environment scale evaluation. Am J Public Health 2003;93:1552-8.

19. Frank LD, Schmid TL, Sallis JF, Chapman J, Saelens BE. Linking objectively measured physical activity with objectively measured urban form-findings from SMARTRAQ. Am J Prev Med 2005;28:117-25. 
20. Giles-Corti B, Donovan RJ. The relative influence of individual, social and physical environment determinants of physical activity. Soc Sci Med 2002;54:1793-812.

21. Centers for Disease Control and Prevention (CDC). Physical activity. Guide to Community Preventive Services Website. 2006 Aug 17. Available online at: www.thecommunityguide.org/pa/.

22. Matson-Koffman DM, Brownstein JN, Neiner JA, Greaney ML. A sitespecific literature review of policy and environmental interventions that promote physical activity and nutrition for cardiovascular health: what works? Am J Health Promot 2005;19:167-93.

23. Kahn EB, Ramsey LT, Brownson RC, et al. The effectiveness of interventions to increase physical activity: a systematic review. Am J Prev Med 2002;22:73-108.

24. Jeffery RW, Utter J. The changing environment and population obesity in the United States. Obes Res 2003;11(Suppl 1):12-22.

25. Brownson RC, Haire-Joshu D, Luke DA. Shaping the context of health: a review of environmental and policy approaches in the prevention of chronic diseases. Annu Rev Public Health 2006;27:341-70.

26. Sallis JF, Bauman A, Pratt M. Environmental and policy interventions to promote physical activity. Am J Prev Med 1998;15:379-97.

27. CDC. Adult participation in recommended levels of physical activityUnited States, 2001 and 2003. MMWR Morb Mortal Wkly Rep 2005; 54:1208-12.

28. CDC. Trends in leisure-time physical inactivity by age, sex, and race/ ethnicity- United States, 1994-2004. MMWR Morb Mortal Wkly Rep 2005;54:991-4.

29. CDC. Prevalence of no leisure-time physical activity - 35 states and the District of Columbia, 1988-2002. MMWR Morb Mortal Wkly Rep 2004; 53:82-6.

30. Arriaza Jones D, Ainsworth BE, Croft JB, Macera CA, Lloyd EE, Yusuf HR. Moderate leisure-time physical activity: who is meeting the public health recommendations? a national cross-sectional study. Arch Fam Med 1998; 7:285-9.

31. Estabrooks PA, Lee RE, Gyurcsik NC. Resources for physical activity participation: does availability and accessibility differ by neighborhood socioeconomic status? Ann Behav Med 2003;25:100-4.
32. Wilson DK, Kirtland KA, Ainsworth BE, Addy CL. Socioeconomic status and perceptions of access and safety for physical activity. Ann Behav Med 2004;28:20-8.

33. Gordon-Larsen P, Nelson MC, Page P, Popkin BM. Inequality in the built environment underlies key health disparities in physical activity and obesity. Pediatrics 2006;117:417-24.

34. Talen E. The social equity of urban service distribution an exploration of park access in Pueblo, Colorado, and Macon, Georgia. Urban Geogr 1997; 18:521-41.

35. Wolch J, Wilson JP, Fehrenbach J. Parks and park funding in Los Angeles: an equity-mapping analysis. Urban Geogr 2005;26:4-35.

36. Powell LM, Slater S, Chaloupka FJ, Harper D. Availability of physical activity-related facilities and neighborhood demographic and socioeconomic characteristics: a national study. Am J Public Health 2006;96: $1676-80$.

37. U.S. Census Bureau. Census 2000 geographic terms and concepts. Washington DC: Government Printing Office, 2000

38. Mujahid M, Diez Roux AV, Morenoff J, Raghunathan TE. Assessing the measurement properties of neighborhood scales: from psychometrics to ecometrics. Am J Epidemiol 2007;165:858-67.

39. Auchincloss AH, Diez Roux AV, Brown DG, O'Meara ES, Raghunathan TE. Association of insulin resistance with distance to wealthy areas - the multi-ethnic study of atherosclerosis. Am J Epidemiol 2007;165:389-97.

40. Guagliardo MF. Spatial accessibility of primary care: concepts, methods and challenges. Int J Health Geogr 2004;3:3.

41. Gatrell A, Bailey T, Diggle P, Rowlingson B. Spatial point pattern analysis and its application in geographical epidemiology. Trans Inst Br Geogr 1996;21:256-74.

42. Census 2000, Summary File 3 (SF 3). 9-25-2002.

43. Spiegelman D, Hertzmark E. Easy SAS calculations for risk or prevalence ratios and differences. Am J Epidemiol 2005;162:199-200.

44. Crompton JL. Financing and acquiring park and recreation resources. Champaign IL: Human Kinetics, 1999.

45. U.S. Department of Health and Human Services (USDHHS). Healthy people 2010: conference edition. Washington DC: USDHHS, 2000. 